YAN Shimei, WANG Zhongming

\title{
Research on the levels and the patterns of human resource integration in $M \& A$ intrapreneurship
}

\author{
(C) Higher Education Press and Springer-Verlag 2008
}

\begin{abstract}
When firms start intrapreneurship by merger or acquisition, the level and pattern of human resource integration becomes a critical issue. However, extant literature has paid scant attentions to this issue. Drawing on the previous researches on M\&A intrapreneurship, the present article collected primary data of the level and pattern of human resource integration in M\&A intrapreneurship by means of in-depth interviews and used content analysis method to structurally analyze the data. The results showed that enterprises engaging in M\&A intrapreneurship generally choose a high or intermediate level of HR integration. Specifically, enterprises at high level of HR integration tend to absorb employees from the acquired directly or recruit afresh employees, while enterprises at intermediate level of HR integration are inclined to adopt an agent-type of integration pattern.
\end{abstract}

Keywords M\&A intrapreneurship, the level of human resource integration, the pattern of human resource integration, content analysis method

摘要 人力资源整合水平和模式是并购式内创业过程中的一个关键且有待深人探讨 的问题, 而以往文献相对缺乏对这一问题的专门研究。基于以往并购整合和内创业 研究结果, 通过深度访谈法获取并购式内创业中人力资源整合水平和整合模式的第 一手资料, 运用内容分析技术对访谈资料进行结构化分析。分析结果显示, 并购式 内创业企业一般选择高或者中等的人力资源整合水平; 在高整合水平上主要采用基

Tanslated from Zhejiang daxue xuebao(Renwen shehui kexueban) 浙江大学学报( 人文社会科学版) (Journal of Zhejiang University (Humanities and Social Sciences)), 2007, 37(1): 178-189

YAN Shimei $(\square)$

School of Management, Zhejiang University, Hangzhou 310058, China

E-mail: shimeiyan@hotmail.com

WANG Zhongming

School of Management, Zhejiang University, Hangzhou 310058, China

E-mail: zmwang@zju.edu.cn 
于直接合并或重新招聘的亲理式整合模式，在中等整合水平上主要采用代理式整合 模式。

关键词 并购式内创业，人力资源整合水平，人力资源整合模式，内容分析方法

\section{Introduction}

In an era of globalization and ever-increasing competitions, enterprises have to adopt numerous ways of self-renewal to enhance their adaptability and to strive for new development. Self-renewal of enterprises includes updating of company strategies, extension of company business scope, innovation in product design or manufacturing techniques, and improvement of management philosophy or corporate culture, etc. Essentially, enterprise self-renewal (including merger \& acquisition) is a way of entrepreneurship(Stopford and Baden-Fuller, 1994; Antoncic and Hisrich, 2001) and HR integration becomes a key issue in M\&A. In the field of entrepreneurship studies, most attentions have been paid to the dimensions of intrapreneurship and the characteristics of intrapreneurs. By comparison, studies on the corporate HR integration level during the M\&A are quite scant. As for the study of integration level of M\&A, extant literature have mostly focused on topics such as employee anxiety, employee satisfaction, employee expectation, etc. There are very few researches concentrating solely on the level and pattern of HR integration. The aims of the present article are to combine intrapreneurship and M\&A integration together to explore specifically the actual HR integration level and patterns adopted in M\&A intrapreneurship.

Researchers have long regarded the HR integration as a determinant of M\&A success to a certain degree(Hunt, 1987; Cartwright and Cooper, 1995; Schuler and Jackson, 2001; Bramson, 2000; Devoge and Shiraki, 2000). The authors conducted a questionnaire survey on 132 decision-makers in 42 enterprises from a wide range of different regions, industries and company sizes. Altogether, these enterprises have carried out $48 \mathrm{M} \& \mathrm{~A}$ intrapreneurship. These decision-makers were required to list five most important items (in order of decreased importance) out of $16 \mathrm{M} \& \mathrm{~A}$ related issues. The survey results showed that three most frequently chosen items were "system integration", "operation evaluation" and "financial performance and business performance evaluations" and the three least frequently chosen items were "corporate culture evaluation", "negotiation" and "employee performance appraisal". The results also demonstrated that before the M\&A, manager usually consider "operation evaluation" and "financial performance and business performance evaluations" as the most and second most crucial issues respectively, while after the M\&A, "system integration" and "personnel integration" become the top priorities. The results illustrate that 
although practitioners in M\&A activities lay great emphases on HR integration, they fail to realize the importance of HR evaluation before M\&A. But there might be another possibility-although practitioners are conscious of the key function of HR integration in M\&A, they do not have systematic HR integration plans and strategies, partly because there is no relevant theory to guide them.

\section{Literature review}

Intrapreneurship is entrepreneurship within an existing organization. It can be defined as a process by which individuals or teams inside established organizations pursue opportunities (such as new business creation, technology innovation, organizational reform or strategy updating, etc.) without regard to the resources they currently control(Antoncic and Hisrich, 2001, 2000). Among these, M\&A is an important and common intrapreneurship form(Yan and wang, 2005, 2006). As for the concept of "human resource integration", drawing on Pablo's view, integration means the making of changes in the functional activity arrangements, organizational structures and systems, and cultures of combining organizations to facilitate their consolidation into a functioning whole. Level of integration refers to the degree of post-merger/post-acquisition change in an organization's technical, administrative, and cultural configuration(Pablo, 1994). In a similar vein, "HR integration" can be defined as reforms in human resources strategies and practices in a post-merger/post-acquisition organization aiming at making the human resources a functional integrated entity, while "the level of HR integration" can be defined as the degree of post-merger/post-acquisition change in an organization's human resources strategies and practices. Since every organization member is deeply embedded in specific HR management practice based on certain HR management philosophy and system, the human resources of any organization consist of both organizational members and corresponding HR management practices. Thus we argue that the HR integration in a post-merger/post-acquisition organization shall include personnel integration and HR management practice integration. Specifically, personnel integration indicates changes in personnel in a post-merger/post-acquisition organization. HR management practice integration refers to changes in HR management system. The level of HR integration denotes the degree of personnel and HR management practice changes in a post-merger/post-acquisition organization. And the pattern of HR integration describes the way of the above changes.

Extant literature relevant to issues of the integration level in M\&A has mostly focused on the organizational integration level. Shrivastaya pointed out three levels of M\&A integration (from the lowest to the highest), namely procedural integration, physical integration, and managerial and sociocultural integration 
(also called overall integration)(Shrivastaya,1986). Schweiger and Walsh described the integration design choices as sitting on a continuum from autonomy to absorption(Schweigher and Walsh, 1990). After giving a definition of the level of integration, Pablo also pointed out that the levels of integration can range from low to high, with autonomy as the lowest level, absorption the highest level. There is also a moderate level. Specifically, Pablo conceptualized the low level of integration as one in which technical and administrative changes are limited to the sharing of financial risk and resources and the standardization of basic management systems and processes to facilitate communication. A moderate level of integration includes increased alterations in the "value chain" as physical and knowledge-based resources are shared or exchanged. Administrative changes at this level may include required selective modifications in reporting relationships and delegation of authority, with such structural changes necessitating reframing cultural bases of decision making. The highest level of integration is conceptualized as being quite inclusive, involving the extensive sharing of all types of resources (financial, physical, and human), generalized adoption of the acquiring organization's operating, control, and planning systems and procedures, and complete structural and cultural absorption of the acquired firm(Pablo, 1994). On the whole, extant studies on the level of integration have not paid direct attention to the level of HR integration in M\&A. However, since HR integration is an indispensable part of organizational integration, study on the classification of different levels of organizational integration will provide theoretical basis and implementation guides for the practice of HR integration in M\&A type of intrepreneurship.

As for the pattern of integration in M\&A, previous literature has mostly been focused on the acculturation modes. Based on the corporate culture interaction between the acquirer and the acquired companies, Nahavandi and Malekzadeh(1988), Elsass and Veiga(1994) identified four modes of acculturation, namely integration, assimilation, separation and deculturation. Integration always leads to some degree of change in both groups' cultures and practices and the flow of cultural elements is balanced because neither group tries to dominate the other; in contrast to integration, assimilation is always a unilateral process in which one group willingly adopts the identity and culture of the other. Separation is likely to take place when members of the acquired organization want to preserve their culture and organizational systems and they refuse to become assimilated with the acquirer in any way or at any level. Deculturation occurs when members of the acquired company do not value their own culture and organizational practices and systems, and they do not want to be assimilated into the acquiring company. As a result, the acquired company is likely to disintegrate as a cultural entity(Nahavandi and Malekzadeh, 1988; Elsass and Veiga, 1994). Similarly, Cartwright and Cooper(1995) identified three 
modes of acculturation: the infusion type (the acquirer infused its corporate culture into the post-acquisition organization), the interactive amalgamation type (the interaction between the cultures of the acquirer and the acquired gives birth to a culture), and independent type (both the acquirer and the acquired preserve independent culture characteristics of their own). The above explorations in the modes of acculturation in M\&A reveal that there is a possibility that specific HR integration modes may exist in M\&A activities. What are the characteristics of these HR integration modes if they do exist?

In the case of HR integration, existing literature has mostly concentrated on the integration-related questions at the individual and team level. Previous researches on employee perception of pressure have revealed that acquisition and the following integration brings great deal of pressure and anxiety to the employees(Bruckman and Peters, 1987; Schweiger and Denisi, 1991). The more different the cultures between the acquirer and the acquired, the longer these pressure and anxiety in employees last(Cartwright and Cooper, 1995; Covinm etal., 1996). Researches on employee expectation have showed that the process of acquisition and integration is also a reconstruction of employee's expectations(Hubbard and Purcell, 2001). Studies on the integration-related questions at the group level have indicated that there usually is a high manager turnover rate after the acquisition, especially in transnational acquisition cases. Further studies reveal that cultural differences and personnel changes in transnational mergers and acquisitions are two determinants of top management turnover(Hayes and Hoag, 1974; Walsh, 1988; Walsh and Ellwood, 1991; Hambrick and Cannella, 1993; Krug and Nigh, 1998). Researches on the management decision-making process have discovered that the choice of integration level is influenced not only by factors at organizational level, but the perceptions of decision makers(Yan and Wang, 2005; Pablo, 1994; Duhaime and Schwenk, 1985; Shanley and Correa, 1985).

To sum up, our literature review shows that there has been little research solely focusing on the discussion of the level and mode of HR integration in M\&A activities. Relevant studies, however, have already laid good foundation for the further exploration of the above two problems.

\section{Methods}

In the present study, we firstly collected primary data of the level and pattern of HR integration in M\&A intrapreneurship activities by means of in-depth interviews. Then by adopting the content analysis method, we structurally analyzed the interview records, hoping to discover the specific levels of HR integration enterprises chosen in M\&A intrapreneurship activities. We also want to 
understand whether there are unique or different $\mathrm{HR}$ integration patterns. If various patterns do exist, we are desirous to find out the characteristics of these patterns.

\subsection{Interview design}

Considering that the HR integration is usually quite time-consuming, it is difficult to collect relevant information and data by mere questionnaire surveys. By comparison, in-depth interview is more flexible. It also allows us to carry out a deeper exploration on selected topics(Yuan, 1997; Wang, 1998). We therefore adopted the method of half-structural interviews to collect data of the level and pattern of HR integration in M\&A activities in this article.

Based on the definitions of "the level of HR integration" and "the pattern of HR integration", we designed two types of questions: (1) After the acquisition, are there any personnel changes in your company? If yes, do these changes involve only the top management or they concern every employee in the organization? (2) After the acquisition, are there any changes in the HR management system? If yes, how do these changes happen? We then conducted trial tests on four enterprises which had implemented M\&A intrapreneurship in Hangzhou city and Ningbo city. Encouraged by the good results with these trail tests, we officially started interviews in other areas. The interview usually lasted about three hours and we saved the data as Microsoft Word-format documents. In this way, we collected primary data of the HR management changes by means of in-depth interviews.

\subsection{The interviewees}

In this study, we firstly chose at random 20 post-acquisition enterprises from Ningbo, Guangzhou, Guiyang, Huzhou and Hangzhou. Altogether, these enterprises carried out $25 \mathrm{M} \& \mathrm{~A}$ activities. We interviewed the M\&A decision-makers and other personnel in these enterprises to find out whether these M\&A activities were intrapreneurship-oriented. Based on the interviews, three non-intrapreneurship-oriented M\&A activities were excluded. In all, we investigated carefully $22 \mathrm{M} \& \mathrm{~A}$ activities in 18 enterprises and interviewed 36 managers. Among these enterprises, 12 are private-owned, 6 state-owned; 2 were small and medium sized enterprises, 16 big sized. Among the 22 M\&A activities, 5 cases were stated-owned enterprises merging/acquiring other state-owned or jointly-ventured emprises; 15 cases were private-owned enterprises other merging/acquiring other state-owned, township enterprises, private-owned enterprises, jointly-ventured emprises, and foreign-funded enterprises. 15 cases were M\&A within the same industry, 7 were cross-industry cases. Enterprises acquired cover a wide variety of industries, including trading, home appliances, 
beverage, real estate, hydropower equipment manufacturing, farm products producing and processing, clothes, textile, chemistry, finance, medicine to telecommunication, etc. The earliest acquisition occurred in 1997, the latest in 2003.

\subsection{Data analysis}

Data analysis method. Considering that there is little research focusing only on the level and pattern of HR integration in M\&A activities in the extant literature, we need to in the present study educe the characteristics of the level and pattern of HR integration from the primary data we had collected from previous interviews. In doing so, we adopted content analysis method due to several reasons. First, as a very important, quantitative-analysis-based technique qualitative analysis approach, the content analysis method has been widely used in management researches(Kolbe and Burnett, 1991; Ma, 2000; Chen, 2001). Secondly, it enables researchers to refer to relevant literature in a standardized way and to quote corresponding data systematically and quantitatively. In other words, the content analysis method can reduce the tendencies of subjectivity and orientations in analysis, thus guarantee the objectivity of one's research(Chen, 2001). By using the content analysis method, we analyzed the interview records sentence by sentence to collect the data of the level and pattern of HR integration.

Most previous researches adopting content analysis method used coding scheme of 2 or more than 2 coders(Kolbe and Burnett, 1991). Since our conclusion needs to be drawn from the primary data, to guarantee the validity of our coding scheme, we utilized the common 3-coder system. Three business management specialists (one professor, one associate professor and one $\mathrm{PhD}$ student) were trained and used to encode the data.

Coding scheme. The process of content analysis consists of two interactive steps, namely we need to explicitly describe content characteristics being detected. We also need to use clearly explained rules to identify and recode these characteristics(Berg, 2001). And establishing explicit identification rules and clear encoding content characteristics rules are of key importance. The process of coding scheme is a process of identifying and ascertaining the specific rules of encoding content characteristics. In the present study, we constructed respectively coding schemes for the level and pattern of HR integration in enterprises carrying out M\&A activities. The former coding scheme is made on the basis of definitions of "HR integration" and "level of HR integration". As defined, the level of HR integration refers to changes in HR after M\&A(Yan and Wang, 2005; Pablo, 1994). And HR changes are twofold: one is personnel change; the other is changes in the HR management practices. Thus the level of HR integration in the M\&A intrapreneurship is judged by two parameters: the degree of personnel changes in a post-acquisition organization and the degree of changes in HR 
management practice. As personnel change is embodied with changes in positions, personnel transfer between the acquirer and the acquired organizations, and the talent transfer between post-acquisition organization and market, and the changes in HR management practice is measured by the degree of application of a new HR management system or the degree of replacement/abandonment of the former HR management system of either the acquirer or the acquired companies, the coding scheme of the level of HR integration include two indexes (personnel changes and changes in HR management practice), consisting of five sub-items.

The development of the coding scheme of the pattern of HR integration is mainly based on the definition of "HR integration" and existing acculturation mode studies. According to the definition, the pattern of HR integration is embodied with the change patterns of personnel and HR management practice. Relevant literature has showed that the pattern of HR integration in post-acquisition organization is co-determined by the culture interaction (such as assimilation or replacement) between the acquirer and the acquired. Thus we can infer that the pattern of HR integration is decided by assimilation or replacement of each other's personnel between the acquirer and the acquired organizations and the corresponding patterns of HR management practices. Meanwhile, as the HR integration pattern reflects the process and characteristics of HR integration, we constructed in the present article a coding scheme of HR integration pattern by means of analyzing the process of HR integration, including change patterns of personnel and HR management practice. The pattern of personnel change refers to personnel assimilation mode, manager accreditation system and managerial position changes. The pattern of HR management practice refers to the deletion, adoption and maintenance of certain HR management practices. During the process of coding scheme construction, we adopted equal distance measurement method and category measurement method.

Testing of Credibility and validity. To test the credibility of content analysis, we adopted the commonest testing procedure-by calculating the degree of consensus among coders. The degrees of consensus on the level and pattern of HR integration among the three coders are shown in Table 1 and Table 2 respectively.

Table 1 Degree of consensus on HR integration level among coders

\begin{tabular}{lc}
\hline Dimension of HR integration level & Degree of consensus among coders \\
\hline Degree of changes in positions after acquisition & 0.86 \\
Degree of personnel transfer between the acquirer and the acquired & 0.91 \\
Degree of talents flow from post-acquisition organization to market & 0.91 \\
Degree of application of brand-new HRMP after acquisition & 0.95 \\
Degree of replacement/deletion of the old HRMP after acquisition & 0.91 \\
\hline
\end{tabular}


Table 2 Degree of consensus on HR integration patterns among coders

\begin{tabular}{lc}
\hline Characterizations of integration patterns & Degree of consensus among coders \\
\hline After acquisition, the number of employees absorbed by the acquirer & 0.86 \\
Patterns of employee absorption & 1.00 \\
After acquisition, the number of managers assigned to the acquired company & 1.00 \\
Positions of the assigned managers & 0.91 \\
Changes in managerial positions after acquisition & 0.91 \\
Patterns of change & 0.82 \\
Deletion of the former HRMP of the acquired & 1.00 \\
Patterns of deletion & 1.00 \\
Absorption of the former HRMP of the acquired & 1.00 \\
Patterns of absorption & 1.00 \\
Maintenance of the former HRMP & 0.95 \\
Patterns of maintenance & 0.95 \\
\hline
\end{tabular}

Table 1 shows that, out of the five aspects of HR integration levels, only the consensus coefficient of "Degree of changes in positions after acquisition" is acceptably low as 0.8 . The rest four coefficients are all over 0.90 . Table 2 lists all 12 category factors of HR integration pattern. Except the two factors of "The number of employees absorbed by the acquirer after acquisition" and "Changes in managerial positions after acquisition", all consensus coefficients are over 0.90 . Thus the content analysis method we used in the study has a high credibility.

To test the validity, we used the common content validity testing method. Since the construction of HR integration level and pattern coding schemes were strictly based on relevant researches, a rigorous definition of HR integration, and large amount of interview data, the present study has pretty good theoretical and practical foundation. In addition, we followed fastidiously scientific coding process: we trained carefully our coders and made precodings. According to the results of the precoding, we deleted items with low credibility and unclear meanings, thus further improved the content validity. Besides, during the coding, coders unanimously agreed that the coding tools used were capable of comprehensively embodying the characteristics of HR integration level and pattern in M\&A intrapreneurship from different dimensions. Taken together, the content analysis used in the present article is of quite high validity.

Statistical analysis of the coding results of HR integration level. As mentioned, the degree of changes in personnel reform consists of three dimensions. Thus the higher each of these dimension, the higher the degree of changes in personnel. The same goes to the degree of changes in HRMP, which is composed of two dimensions. To further reveal the specific dimensions embodying HR changes, we analyzed the coding results of the above five dimensions, as shown in Table 3 and Table 4. 
Table 3 Coding results of degree of changes in personnel

\begin{tabular}{llrcr}
\hline Dimension of degree of changes in personnel & Degree & Frequency & Percentage(\%) & Mean \\
\hline A. Degree of changes in positions & 1 low & 20 & 30.30 & \\
& 2 average & 2 & 3.03 & 2.36 \\
B. Degree of personnel transfer between & 3 high & 44 & 66.67 & \\
the acquirer and the acquired & 1 low & 26 & 39.40 & \\
& 2 average & 3 & 4.55 & 2.17 \\
C. Degree of talent flow from & 3 high & 37 & 56.06 & \\
the post-acquisition organization & 1 low & 49 & 74.24 & \\
to market & 2 average & 10 & 15.15 & 1.36 \\
\hline
\end{tabular}

Table 3 exhibits that among the three dimensions of personnel change, A and $\mathrm{B}$ have higher degree of changes. Their frequencies are 44 and 37 respectively. Also, the means of A (2.36) and B (2.17) are much higher than C (1.36). All these indicate that changes in personnel in $M \& A$ intrapreneurship are mainly embodied in Dimension A and B. We can thus infer that most employees still stay in their former organizations even after the acquisition.

Table 4 Coding results of degree of changes in HRMP

\begin{tabular}{llrrr}
\hline Dimension of degree of changes in HRMP & Degree & Frequency & Percentage(\%) & Mean \\
\hline A. Degree of application of new & 1 low & 62 & 93.94 & \\
HRMP after acquisition & 2 average & 1 & 1.61 & 1.11 \\
& 3 high & 3 & 4.55 & \\
B. Degree of replacement/deletion & 1 low & 10 & 15.15 & \\
of the former HRMP & 2 average & 3 & 4.55 & 2.65 \\
after acquisition & 3 high & 53 & 80.30 & \\
\hline
\end{tabular}

As indicated in Table 4, dimension $\mathrm{B}$ has a higher degree of change. Its frequency and mean are 53 and 2.65 respectively and the mean is approaching the high characterization value $(=3)$. By comparison, Dimension A has a much lower degree of change. The frequency of "low" is 62 , accounting for $93.94 \%$ of the total frequency. In addition, its mean is a low 1.11, approaching the low characterization value $(=1)$. Thus we can infer that changes in HRMP are concentrated on Dimension B.

As for the level of HR integration in M\&A intrapreneurship, since changes of personnel and HRMP are determinants of the level of HR integration, the higher the changes in personnel and HRMP, the higher the level of HR integration and vice versa. In cases of a high degree of personnel changes and a low degree of HRMP changes or vice versa, or both the degree of personnel and HRMP changes are at intermediate level, the level of HR integration should also be at an 
intermediate level. Taken together, the levels of HR integration in a post-acquisition organization may be one of the following five characterizations.

Table 5 Characterizations of level of HR integration

\begin{tabular}{lll}
\hline High level & Intermediate level & Low level \\
\hline DCP*: high & DCP: high & DCP: low \\
DCHRMP*: high & DCHRMP: low & DCHRMP: low \\
& DCP: low & DCP: low \\
& DCHRMP: high & DCHRMP: intermediate \\
& DCP: intermediate & DCP: intermediate \\
& DCHRMP: intermediate & DCHRMP: low \\
\hline
\end{tabular}

Notes: DCP stands for Degree of Changes in Personnel; DCHRMP stands for Degree of Changes in Human Resources Management Practice

Based on the analysis on the coding results of degrees of changes in personnel and HRMP in post-acquisition organizations and the characterizations of different levels of HR integration, we future analyzed the coding schemes of HR integration level. The results show that HR integration mainly concentrates at the high level with a frequency of $42(63.64 \%)$. The percentages of intermediate and low levels of HR integration are only $25.67 \%$ and $10.61 \%$ respectively. The results imply that in M\&A activities, enterprises tend to choose high or intermediate levels of HR integration, with the exception of only a small fraction of enterprises.

Statistical analysis of the coding results of HR integration patterns. As mentioned, the patterns of HR integration are embodied with patterns of change in personnel and in HRMP. We therefore coded respectively these two patterns of changes. The coding results are show in Table 6 and 7.

Table 6 shows that the mean of employees absorbed by the acquirer from the acquired is 2.89 , approaching the high characterization value $(=3)$. And the value of the "high" frequency is $62(93.94 \%)$. Statistics show that personnel absorption is realized mainly through two ways, namely direct personnel amalgamation (frequency $=46$ ) and recruit afresh employees (frequency $=20$ ). The acquirer may assign a lot or few managers (both have a frequency of 32) to different positions in the acquired organization. As for the changes in managerial positions, the frequencies of big change and small change are 37 and 22 respectively. There are three patterns of change: appoint afresh all managers (frequency $=27$ ), keep the former managers in the acquired company (frequency $=21$ ), and make minor managerial position changes (frequency $=18$ ). Thus we can infer that in M\&A intrapreneurship, there are two main personnel changes modes: absorb in large number the employees from the acquired company, assign a lot managers or appoint afresh new managers in the acquired company; or absorb in large number 
the personnel from the acquired company while make only small changes in managerial positions.

Table 6 Coding results of personnel changes

\begin{tabular}{|c|c|c|c|c|}
\hline Dimensions of personnel change & Concrete ways & equency & Percentage(\%) & Mean \\
\hline \multirow{3}{*}{$\begin{array}{l}\text { After acquisition, the number } \\
\text { of employees absorbed } \\
\text { by the acquirer }\end{array}$} & Few & 3 & 4.55 & \multirow{3}{*}{2.89} \\
\hline & Average & 1 & 1.52 & \\
\hline & A lot & 62 & 93.94 & \\
\hline \multirow[t]{2}{*}{ Patterns of employee absorption } & Direct amalgamation & 46 & 69.70 & \\
\hline & Recruit afresh employees & 20 & 30.30 & \\
\hline \multirow{3}{*}{$\begin{array}{l}\text { After acquisition, the number } \\
\text { of managers assigned to } \\
\text { the acquired company }\end{array}$} & Few & 32 & 48.48 & \multirow{4}{*}{2.00} \\
\hline & Average & 2 & 3.03 & \\
\hline & A lot & 32 & 48.48 & \\
\hline \multirow{2}{*}{ Positions of the assigned managers } & s $\quad$ Similar positions & 18 & 27.27 & \\
\hline & Different managerial positions & ns 48 & 72.73 & \\
\hline \multirow{3}{*}{$\begin{array}{l}\text { Changes in managerial positions } \\
\text { after acquisition }\end{array}$} & Little & 22 & 33.33 & \multirow{3}{*}{2.23} \\
\hline & Average & 7 & 10.61 & \\
\hline & A lot & 37 & 56.06 & \\
\hline \multirow[t]{3}{*}{ Patterns of change } & Appoint afresh all managers & 27 & 40.91 & \\
\hline & Make only partial adjustment & 18 & 27.27 & \\
\hline & Keep the former managers & 21 & 31.82 & \\
\hline
\end{tabular}

Table 7 Patterns of changes in HRMP

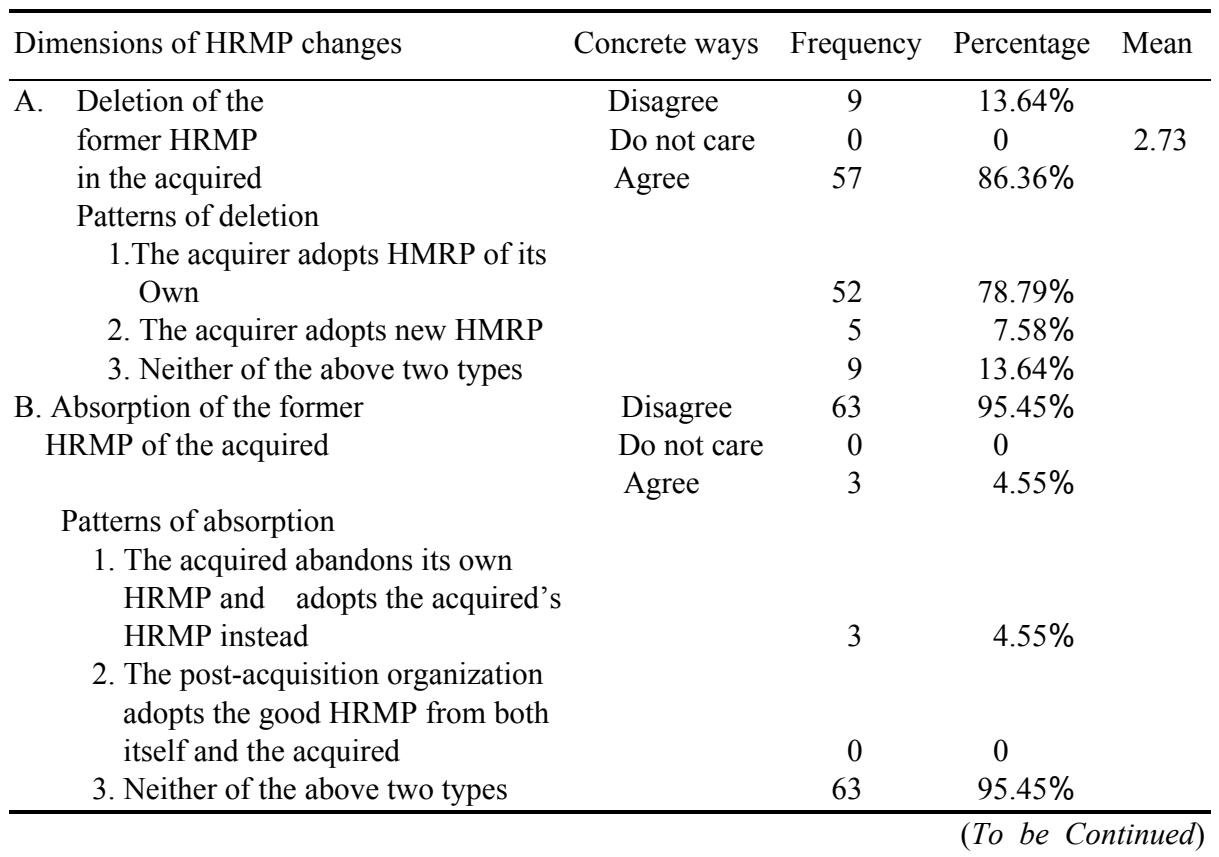




\begin{tabular}{|c|c|c|c|c|}
\hline \multicolumn{5}{|c|}{ (Continued) } \\
\hline Dimensions of HRMP changes & Concrete ways & Frequency & Percentage & Mean \\
\hline C. Maintenance of the & Disagree & 59 & $89.39 \%$ & \\
\hline former HRMP & Do not care & 0 & 0 & \\
\hline & Agree & 7 & $10.61 \%$ & \\
\hline Patterns of maintenance & & & & \\
\hline 1. maintain friendly independence & & 7 & $10.61 \%$ & \\
\hline 2. maintain hostile independence & & 0 & 0 & \\
\hline 3. Neither of the above two types & & 59 & $89.39 \%$ & \\
\hline
\end{tabular}

Table 7 depicts that among the dimensions of changes in HRMP, Dimension A has the highest frequency of "agree" of $57(=86.36 \%)$; among the deletion patterns, "the acquirer adopts its own HRMP in the post-acquisition organization" has the highest frequency of "disagree" of $52(=78.79 \%)$ and Dimensions B and $\mathrm{C}$ have the highest and second highest frequency of "disagree" of $63(=95.45 \%)$ and $59(=89.39 \%)$ respectively. Thus we can infer that the most prevailing pattern of HRMP change in M\&A intrapreneurship is: the acquirer deletes the former HRMP of the acquired and adopts its own HRMP in the post-acquisition organization. There are also other change patterns existing, such as the acquirer and the acquired may maintain their own HRMP in a friendly way; or the acquired may abandon its former HRMP completely and adopt instead the HRMP of the acquirer. These two change patterns, however, have rather low frequencies, accounting for only $10.61 \%$ and $4.55 \%$ respectively.

Since the pattern of HR integration is a result of the combination of patterns of personnel changes and HRMP changes, based on the analysis of the coding results of the change patterns, we identified five HR integration patterns as below. In Pattern A: large numbers of employees are absorbed by the acquirer (direct personnel amalgamation); many managers are sent to the acquired company (to many different managerial positions); big changes in managerial positions (appoint afresh all managers or make partial adjustment); deletion of the acquired's former HRMP (replace them with the acquirer's HRMP). In Pattern B: large numbers of employees are absorbed by the acquirer (recruit afresh new employees); many managers are sent to the acquired company (to many different managerial positions); big changes in managerial positions (appoint afresh all managers or make partial adjustment); deletion of the acquired's former HRMP (replace them with the acquirer's HRMP). In Pattern C: large numbers of employees are absorbed by the acquirer (direct personnel amalgamation); few managers are sent to the acquired company (to few different managerial positions); small changes in managerial positions (keep the former managers of 
the acquired); deletion of the acquired's former HRMP (replace them with the acquirer's HRMP). In Pattern D: large numbers of employees are absorbed by the acquirer (direct personnel amalgamation); few managers are sent to the acquired company(to the same managerial positions); small changes in managerial positions (keep the former managers of the acquired); both the acquirer and the acquired maintain the HRMP of their own (maintain a friendly independence). In Pattern E: large numbers of employees are absorbed by the acquirer (direct personnel amalgamation); few managers are sent to the acquired company (to few different managerial positions); small changes in managerial positions (keep the former managers of the acquired); deletion of the acquirer's former HRMP (replace them with the acquired's HRMP).

A further analyses on the coding results of the above HR integration patterns show that Pattern A, B and C all have pretty high frequencies $(=16,21,20$ respectively). Altogether, these three patterns of integration account for as high as $86.36 \%$ in the total frequency $(=24.24 \%, 31.82 \%, 30.30 \%$ respectively), indicating that the integration of HR in M\&A activities mainly adopts one of these three patterns. The results also exhibit that few HR integration use Pattern $\mathrm{D}$ and $\mathrm{E}$ since both of them have very low frequencies ( $=6$ and 3 respectively). Together they only account for $13.64 \%$ in the total frequency.

\section{Discussion and conclusion}

We collected in the present study primary data of the levels and patterns of HR integration in M\&A intrapreneurship by means of in-depth interview. We then adopted content analysis method to structurally analyze the data and identified levels and patterns of HR integration chosen in M\&A activities.

The results of HR integration level analysis shows that: (1) personnel changes are mainly made of three aspects, namely changes in managerial positions, personnel transfer between the acquired and the acquirer, and the replacement of HRMP of one party of the acquisition. This means in M\&A, the initiator of the intrapreneurship usually absorbs members from the acquired in large numbers, but put these new talents under a new HRM system. (2) When an enterprise engages in intrapreneurship, it usually chooses high/intermediate levels, instead of low level of HR integration

Analyses of HR integration pattern show that: (1) As the mainstream HR integration patterns in M\&A intrapreneurship, the acquirer usually absorbs the talents from the acquired in large numbers by means of direct personnel amalgamation or recruit afresh employees. The acquirer is also likely to delete the former HRMP of the acquired and replace them with its own. (2) As above, we identified five HR integration patterns adopted in M\&A intrapreneurship. 
Among these five patterns, the first three are frequently used. Pattern D is not so common, while Pattern E is rarely used in M\&A. (3) By comparison, Pattern A and $\mathrm{B}$ have a lot of similarities for both of them have higher degree of personnel changes. The acquirer absorbs completely employees from the acquired, sends a lot of new managers to the acquired and applies its own HRMP in the acquired. The only difference between these two patterns is the former adopts a direct personnel amalgamation approach while the latter recruits afresh employees. We call the two as "in-person-management" HR integration patterns, meaning that the acquirer governs the acquired in person after the M\&A. In a similar vein, Pattern $\mathrm{C}$ and $\mathrm{D}$ also have a lot in common for both of them have intermediate degree of personnel changes. The acquirer absorbs in large number employees from the acquired and sends few new managers to the acquired company. In these two patterns, the acquirer relies on the former managers of the acquired company and there are little changes in managerial positions. The only difference between these two patterns is the former deletes the former HRMP of the acquired while the latter maintains the former HRMP of both the acquirer and the acquired. We call the two as "agent" HR integration patterns, meaning that the acquirer relies on the former managers of the acquired to govern the acquired company and there is little degree of changes in HR. As for Patten E, since it is quite unique and is rarely adopted in M\&A activities, we are not going to discuss it in details in the present article.

After combining the analysis results of the levels and patterns of HR integration, we found that in M\&A intrapreneurship, enterprises tend to choose high or intermediate levels of HR integration. At the high level of HR integration, enterprises often adopt the "in-person-management" integration patterns by means of amalgamating directly personnel from the acquired or recruiting afresh new employees, while at the intermediate level of HR integration, enterprises usually choose the "agent" integration pattern.

During the course of intrapreneurship through M\&A, the specific level of HR integration an enterprise chooses is always consistent with the objectives of the acquisition. If an enterprise conducts acquisition for the purpose of the realization of synergy potentials, low level of HR integration will suffice. But is the objective is to fulfill the resources synergy potentials, higher level of integration becomes a must. When acquisition is for the aim of operation synergy effects, there should be an all-round integration at high level(Nahavandi and Malekzadeh, 1988; Olie, 1994). Drawing on the transaction cost theory, acquisition is an internalized governance structure which integrates two separate organizations into one entity. The consequences are twofold: it reduces the transaction costs but increases the internal governance costs. Thus there is a possibility that although a high level of HR integration may theoretically facilitates the fulfillment of the organization-interdependence-based synergy 
potentials, it may also gives rise to inter-organizational conflicts and coordination costs, resulting in antagonism instead of synergism(Pablo, 1994; Yan and Wang 2002). Only when the acquisition purpose requires a high integration level, will an enterprise tolerates the high governance costs caused by the high integration level. Since the purpose of M\&A activities is intrapreneurship, resource and operation synergies have absolute priority over mere financial synergy. Thus enterprises tend to choose high/intermediate levels of HR integration. This result is in line with Pablo's conclusion in an empirical study, which showed that the stronger the strategic task force of an acquiring company, the higher level of integration will be adopted in the post-acquisition organization. Strategic task force means the degree of exchanges of key technologies, capabilities or resources between the acquirer and the acquired. In M\&A activities, the purpose of acquisition is to realize intrapreneurship, thus all-round exchange of technology, know-how, talents between the acquirer and the acquired company is of key importance. In other words, the strategic task force of intrapreneurship is very strong, thus enterprises seeking intrapreneurship through M\&A tend to choose high integration levels.

Acknowledgements This paper is supported by the Major Program of the National Natural Science Foundation of China (Grant No. 70232010 and No. 70672046).

\section{References}

Antoncic B, Hisrich R D(2001). Intrapreneurship: Construct refinement and cross cultural validation. Journal of Business Venturing, 16: 495-527

Antoncic B, Hisrich R D(2000). Intrapreneurship modeling in transition economies: A comparison of Slovenia and the United States. Journal of Developmental Entrepreneurship, $5(1), 21-40$

Antoncic B(2001). Organizational processes in intrapreneurship: A conceptual integration. Journal of Enterprising Culture, 9(2): 221-235

Berg B L(2001). Qualitative Research Methods for the Social Sciences ( 4th Ed). Boston: Allyn \& Bacon

Bramson R N(2000). HR's role in mergers and acquisitions. Training \&Development, (10): $59-66$

Bruckman J C, Peters S C(1987). Mergers and acquisitions: The human equation. Employment Relations Today, 141(1): 55-63

Cartwright S, Cooper C L(1995). Organizational marriage "Hard" Versus "Soft" Issues? Personnel Review, 24(3): 32-42

Cartwright S, Coopler C L(1993). The role of culture compatibility in successful organizational marriage. Academy of Management Executive, 7(2): 57-70

Chang J(1998). Model of corporate entrepreneurship: Intrapreneurship and Exopreneurship. Borneo Review, 9(2): 187-213

Chen Weijun(2001). Comparison between Bibliometric method and content analysis method. 
Information Science, (8): 884-886

Covin T J, Sightler K W, Kolenko T A, et al(1996). An investigation with the merger. Journal of Applied Behavioral Science, 32(2): 125-146

Dess G G, Ireland, R D, Zahza,S A, et al(2003). Emerging Issues in Corporate Entrepreneurship. Journal of Management, 29(3): 351-378

Devoge S, Shiraki J(2000). People factors: the missing link in merger success. Compensation \& Benefits Management, (4): 26-32

Duhaime I M, Schwenk, C R(1985). Conjectures on cognitive simplification in acquisition and divestment decision making. Academy of Management Review, 10(2): 287-295

Elsass P M, Veiga J F(1994). Acculturation in acquired organizations: A force-field perspective. Human Relations, 47(4): 431-448

Hambrick D C, Cannella J R A A(1993). Relative standing: A framework for understanding departures of acquired executives. Academy of Management Journal, 36(4): 733-762

Hayes R H, Hoag G H(1974). Post-acquisition retention of top management. Mergers and Acquisitions, 9(2): 8-18

Hubbard N, Purcell J(2001). Managing employee expectations during acquisitions. Human Resource Management Journal,11 (2): 17-33

Hunt J(1987). How people get overlooked in takeovers. Personnel Management, (7): 24-26

Kolbe R H, Burnett M S(1991). Content-analysis research: An examination of applications with directives for improving research reliability and objectivity. Journal of Consumer Research, 18(9): 243-250

Krug J A, Nigh D(1998). Top management departures in cross border acquisitions: Governance issues in an international context. Journal of International Management, (4): $267-287$

Ma Wenfeng(2000). Application of content analysis methods in the social and scientific information science(in Chinese). Information Science, (4): 346-349

Nahavandi A, Malekzadeh A R(1988). Acculturation in mergers and acquisitions. Academy of Management Review, 13(1): 79-90

Olie R(1994). Shades of culture and institution in international mergers. Organization Studies, 15(3): 381-405

Pablo A L(1994). Determinant $\mathrm{s}$ of acquisition integration level: A decision making perspective. Academy of Management Journal, 37(4): 803-836

Schuler R S, Jackson S E(2001). HR issues and activities in mergers and acquisitions. European Management Journal, 19(3): 239-253

Schweiger D M, Denisi A S(1991). Communication with employees following a merger: A longitudinal field experiment. Academy of Management Journal, 34(1): 110-135

Schweiger D M, Walsh J P(1990). Merger and acquisitions: An interdisciplinary view. Rowland K M, Ferris G R(ed): Research in Personnel and Human Resource Management. Greenwich, CT: JAI Press, (8): 41-107

Shanley M T, Correa M E(1992). Agreement between top management teams and expectations for post acquisition performance. Strategic Management Journal, 13: 245-266

Shrivastaya P(1986). Post-merger Integration. Journal of Business Strategy, 7(1): 65-76

Stopford J M, Baden-Fuller F(1994). Creating corporate entrepreneurship. Strategic Management Journal, 15: 521-536

Walsh J P, Ellwood J W(1991). Mergers, acquisitions, and the pruning of managerial deadwood. Strategic Management Journal, 36: 671-700

Walsh J P(1988). Top management turnover following mergers and acquisitions. Strategic Management Journal, (9): 173-183 
Wang Zhongming(1998). Psychology research methods. Beijing: People's Education Publishing House(in Chinese)

Yan Shimei, Wang Zhongming(2002). Strategic alliances and M\&A: A comparion of two organization models(in Chinese). Studies in Science of Science, (3): 272-275

Yan Shimei, Wang Zhongming(2005). The selection on the level of human resource integration in merger and acquisition intrapreneurship: An empirical study. Management World (in Chinese), (9):107-118

Yan Shimei, Wang Zhongming(2006). The tactics of controlling human resource integration risk in merger and acquisition intrapreneurship: Case study. Management World (in Chinese), (6): 119-129, 140

Yuan Fang(1997). Social Research Methods(in Chinese). Beijing: Peking University Press 